Article

\title{
Dynamics of the Honeybee (Apis mellifera) Gut Microbiota Throughout the Overwintering Period in Canada
}

\author{
Naomie Bleau ${ }^{1,2,3, *}$, Sidki Bouslama ${ }^{1,2,3}$, Pierre Giovenazzo ${ }^{1,2}(\mathbb{D})$ and Nicolas Derome ${ }^{1,3}$ \\ 1 Biology Departement, Laval University, 1045 Avenue de la Médecine, Quebec City, QC G1V 0A6, Canada; \\ sidki.bouslama.1@ulaval.ca (S.B.); pierre.giovenazzo@bio.ulaval.ca (P.G.); nicolas.derome@bio.ulaval.ca (N.D.) \\ 2 Centre de Recherche en Sciences Animales de Deschambault (CRSAD), 120a Chemin du Roy, \\ Deschambault, QC G0A 1S0, Canada \\ 3 Institut de Biologie Intégrative et des Systèmes (IBIS), Laval University, 1030 Avenue de la Médecine, \\ Quebec City, QC G1V 0A6, Canada \\ * Correspondence: naomie.bleau.1@ulaval.ca
}

Received: 25 June 2020; Accepted: 27 July 2020; Published: 29 July 2020

\begin{abstract}
Microbial symbionts inhabiting the honeybee gut (i.e., gut microbiota) are essential for food digestion, immunity, and gut protection of their host. The taxonomic composition of the gut microbiota is dynamic throughout the honeybee life cycle and the foraging season. However, it remains unclear how drastic changes occurring in winter, such as food shortage and cold weather, impact gut microbiota dynamics. The objective of this study was to characterize the gut microbiota of the honeybee during the overwintering period in a northern temperate climate in Canada. The microbiota of nine honeybee colonies was characterized by metataxonomy of 16S rDNA between September 2017 and June 2018. Overall, the results showed that microbiota taxonomic composition experienced major compositional shifts in fall and spring. From September to November, Enterobacteriaceae decreased, while Neisseriaceae increased. From April to June, Orbaceae increased, whereas Rhizobiaceae nearly disappeared. Bacterial diversity of the gut microbiota decreased drastically before and after overwintering, but it remained stable during winter. We conclude that the honeybee gut microbiota is likely to be impacted by the important meteorological and dietary changes that take place before and after the overwintering period. Laboratory trials are needed to determine how the observed variations affect the honeybee health.
\end{abstract}

Keywords: microbiome; gut dysbiosis; symbiont; winter; pollinator

\section{Introduction}

All animals, including insects, host a variety of microorganisms (bacteria, archaea, yeast, viruses) in their digestive tract that is defined as their gut microbiota [1]. The honeybee (Apis mellifera) harbors a simple core microbiota in the gut, mostly dominated by six bacterial families: Lactobacillaceae, Acetobacteriaceae (Parasaccharibacter apium), Rhizobiaceae (Bartonella apis), Bifidobacteriaceae, Neisseriaceae (Snodgrassella alvi) and Orbaceae (Gilliamella apicola, Frischella perrara) [2-4].

The relationship between the gut microbiota and its host is mutualistic [5]. The gut offers a safe and nutrient-rich environment for the microbes to thrive, while microorganisms perform many tasks related to nutrition [6,7], immunity [8-10] and gut epithelium protection [11]. The honeybee gut is first colonized with microorganisms through contact with nurse bees and various foods during their larval stage. However, during their metamorphosis into pupae, the gut epithelium is excreted with gut bacteria by defecation [12]. The emerging bee is axenic and acquires its mature gut microbiota 
during its first week of life mostly through trophallaxis, faecal-oral interaction [13] and contact with hive material [14].

During the adult life of the honeybee, factors such as food quality, parasite presence and chemicals impact its microbiota composition and diversity [15]. Asian honeybees (Apis ceranae) fed with beebread have a different and more diverse microbiota compared to those fed with plain sugar syrup [16]. Moreover, feeding bees aged pollen causes a reduction of Snodgrassella alvi in the honeybee gut, and an increase of Frischella perrara, a bacterium associated with impaired development [17]. The access to fresh and diverse food seems essential to maintain a normal and diverse gut microbiota.

In colonies infected by the parasitic mite Varroa destructor, there are an increased number of S. alvi and a decrease of Lactobacillaceae in the gut of workers [18,19]. Additionally, the microbiota of the parasitized larvae is similar to that of $V$. destructor [20]. Artificial infection of bees with Nosema ceranae, a pathogenic microsporidium, also alters the microbiota and provokes a rise in the abundance of Gilliamella apicola [21]. To control these parasites, beekeepers frequently use chemicals such as fumagilin (against Nosema spp.) and oxalic acid (against $V$. destructor). However, these products are known to reduce the diversity and bacterial abundance of the honeybee gut microbiota [22,23].

To explore the combined impact of these factors on the honeybee gut microbiota, Ludvigsen et al. studied the bacterial community of the honeybee midgut during part of a beekeeping season, from May to October. They found that G. apicola dominates the midgut in May and is replaced by S. alvi later in summer. They also observed a significant increase in diversity between May and June. Their results suggest that the honeybee gut microbiota is mainly driven by food availability and bee demography during the foraging season [14].

However, to our knowledge, the evolution of the honeybee gut microbiota from October to May has not yet been described. In the northern climates typical of north-eastern Canada, overwintering colonies experience unique environmental conditions and must be prepared accordingly. Starting in early fall, colonies are fed concentrated sucrose syrup (2:1) to ensure that they have sufficient food stores. Colonies are then treated against $V$. destructor with various acaricides and Nosema spp. with a fungicide, Fumidyl-B ${ }^{\circledR}$. Afterwards, when the average daytime temperature is around $0{ }^{\circ} \mathrm{C}$, colonies are overwintered indoors in a common environmentally controlled room $\left(3-5{ }^{\circ} \mathrm{C}\right.$ and $\left.30-40 \% \mathrm{RH}\right)$ or outdoors with added insulation. Overwintering usually lasts from early December to April and is a critical period for the Canadian beekeeping industry. In the past 10 years, Canadian beekeepers have experienced large losses, with an average of $26 \%$ of their colonies dying while wintering or early in spring [24].

Colony behavior and honeybee physiology change significantly in winter [25]. Overwintering bees have a lifespan of over 100 days, compared to an average of 30 days for summer bees [26]. In winter, they form a compact cluster around their queen and generate heat through flight muscle vibration [27]. Throughout the overwintering period, honeybees are confined within the hive and do not defecate [28]. As a result, Nosema spp. spore load increases in the midgut of winter bees, impacting their gut microbiota [21] and health [29].

This combination of environmental, nutritional, and behavioral changes unique to a northern climate could impact the bacterial communities living in the honeybee gut. In this research, we investigated the compositional and structural shifts taking place in worker bees' gut from September to June in colonies living in north-eastern Canada. We hypothesize that gut microbiota composition and diversity will follow a seasonal trend. We expect that microbial diversity will decrease in fall and winter because of antiparasitic treatments, isolation and the absence of plants to forage, which are an important source of microorganisms [30]. Knowing how the microbial communities are affected by seasonal changes will allow us to identify gut dysbiosis in honeybees and propose probiotic nutritional supplements to improve the health of wintering colonies. 


\section{Materials and Methods}

\subsection{Environment and Colony Management}

No permits were required for this research. The study took place at the Centre de Recherche en Sciences Animales de Deschambault and was conducted on nine honeybee colonies of similar strength (total brood area) selected from among the livestock at our bee research facility (CRSAD, Deschambault, QC, Canada; $46^{\circ} 40^{\prime} 30.0^{\prime \prime} \mathrm{N}, 71^{\circ} 54^{\prime} 52.3^{\prime \prime} \mathrm{O}$ ). During the setup phase, young sister queens were introduced in the colonies in July 2017. Following acceptance of the queens, the colonies were moved to two apiaries located in Deschambault, Quebec, near the bee research facility. The experimental phase of the project took place between September 2017 and June 2018. At the beginning of September, honey supers were removed, and colonies were reduced to one brood chamber. Fall feeding started in mid-September and all colonies were given $24 \mathrm{~L}$ of a sucrose 2:1 solution using a top box feeder (Wooden Miller feeder \# FE-1100 from Propolis-etc., Beloeil, QC, Canada). Colonies received a Thymovar anti-varroa treatment starting on September 12, followed by an oxalic acid treatment on November 5 (drip method: $35 \mathrm{~g} / \mathrm{L}$ in a sucrose 1:1 solution, $5 \mathrm{~mL}$ between every frame of the hive body crowded with honeybees). Colonies were wintered indoors in an environmentally controlled room (4-5 $\left.{ }^{\circ} \mathrm{C}, 50-60 \% \mathrm{RH}\right)$ from 22 November 2017 to 20 April 2018, and then moved to two spring apiaries until the end of June 2018.

\subsection{Honeybee Sampling}

Bees were sampled at four key times: September 6, after the last honey flow; November 2, after the anti-varroa treatments and before entering the wintering room; April 27, after wintering and removal from the wintering room; and June 1, during the first honey flow of the year. Samples consisted of approximately 100 nurse bees shaken off brood frames and immediately freeze-killed on dry ice. Samples were then brought to the lab and stored in a freezer at $-86{ }^{\circ} \mathrm{C}$ (Thermofisher $-86{ }^{\circ} \mathrm{C} \mathrm{FORMA}$ 908, Waltham, MA, USA).

\subsection{Sample Preparation and Sequencing}

To assess bacterial composition of the honeybees' microbiota, V3-V4 hyper-variable regions of the $16 \mathrm{~S}$ small subunit (SSU) rDNA gene were targeted. To this end, the midgut of 20 bees per colony was removed from their abdomen with sterile forceps and pooled together in $2 \mathrm{~mL}$ microtubes. Then, $800 \mu \mathrm{L}$ of sterile salt homogenizing buffer $(5 \mathrm{M} \mathrm{NaCl}, 1 \mathrm{M}$ Tris- $\mathrm{HCl}$ pH 8.0 and 0.5M EDTA) and sterile $4.5 \mathrm{~mm}$ metal beads were added to the microtubes. The pooled midguts were vortexed for one minute to homogenize them.

Total DNA was extracted using a salt-extraction method [31]. First, $440 \mu \mathrm{L}$ of the midgut homogenate and $20 \mu \mathrm{L}$ of lysozyme $(25 \mathrm{mg} / \mathrm{L})$ were mixed and incubated at $37{ }^{\circ} \mathrm{C}$ for $1 \mathrm{~h}$. Then, $44 \mu \mathrm{L}$ of $20 \%$ SDS and $8 \mu \mathrm{L}$ of proteinase $\mathrm{K}(20 \mathrm{mg} / \mathrm{mL})$ were added and vortexed. The samples were incubated at $56{ }^{\circ} \mathrm{C}$ overnight, rotating at a speed of $600 \mathrm{rpm}$. The next day, $4 \mu \mathrm{L}$ RNase $(10 \mathrm{mg} / \mathrm{mL})$ was added to the tubes and incubated for an hour at $37^{\circ} \mathrm{C}$. Then, $300 \mu \mathrm{L}$ of $6 \mathrm{M} \mathrm{NaCl}$ was added to each sample before being vortexed $(1 \mathrm{~min})$ and centrifuged $\left(20 \mathrm{~min}, 16,000 \times g, 4^{\circ} \mathrm{C}\right)$. The supernatant was transferred to a new $1.5 \mathrm{~mL}$ microtube, and the same volume of cold isopropanol $\left(-20^{\circ} \mathrm{C}\right)$ was added. The tubes were gently mixed and incubated at $-20^{\circ} \mathrm{C}$. After $30 \mathrm{~min}$, the tubes were centrifuged (20 $\mathrm{min}, 16,000 \times \mathrm{g}, 4{ }^{\circ} \mathrm{C}$ ) and the supernatant was discarded. Then, $200 \mu \mathrm{L}$ of cold ethanol $\left(-20^{\circ} \mathrm{C}\right)$ was added to the tubes, followed by a last centrifugation $\left(10 \mathrm{~min}, 16,000 \times g, 4^{\circ} \mathrm{C}\right)$. The supernatant was discarded once more, and the DNA pellet was left to dry before being placed in $100 \mu \mathrm{L}$ of DNAand RNA-free water. The DNA was kept at $-20^{\circ} \mathrm{C}$ until needed.

The PCR amplification of the V3-V4 region of the bacterial 16S rDNA gene was carried out with the 803R 5'-GTG ACT GGA GTT CAG ACG TGT GCT CTT CCG ATC TCT ACC RGG GTA TCT AAT CC-3') and 347F (5'-ACA CTC TTT CCC TAC ACG ACG CTC TTC CGA TCT GGA GGC AGC AGT RRG GAA T-3') primers. The PCR reactions were performed in a total volume of $50 \mu \mathrm{L}$ containing 
$10.5 \mu \mathrm{L}$ sterile water, $3 \mu \mathrm{L}$ DNA template, $2.5 \mu \mathrm{L}$ of each primer, $10 \mu \mathrm{L}$ of Reaction Buffer $5 \times, 10 \mu \mathrm{L}$ of GC enhancer $5 \times$ and $0.5 \mu \mathrm{L}$ of Q5 Taq Polymerase (New England Biolabs, Ipswich, MA, USA). The PCR conditions were as follows: denaturation for $2 \mathrm{~min}$ at $98^{\circ} \mathrm{C}$, followed by 35 cycles of $10 \mathrm{~s}$ at $98{ }^{\circ} \mathrm{C}, 30 \mathrm{~s}$ at $60{ }^{\circ} \mathrm{C}$ and $30 \mathrm{~s}$ at $72{ }^{\circ} \mathrm{C}$ for the amplification, and final extension at $72{ }^{\circ} \mathrm{C}$ for $2 \mathrm{~min}$. PCR products (approximately $500 \mathrm{pb}$ ) were visualized by electrophoresis in 2\% $(w / v)$ agarose gels and purified with AMPure XP beads (Beckman Coulter Life Sciences, Brea, CA, USA). The quality of amplicons was assessed using a spectrophotometer (NanoDrop2000, ThermoFisher Scientific). A second PCR amplification was conducted to add unique barcodes to every sample. The same steps performed for the first PCR were followed to visualize, purify and quantify the amplicons. The samples were pooled in an equimolar ratio and sent to the Plateforme d'Analyses Génomiques of the Institut de Biologie Intégrative et des Systèmes (Québec, Canada) for sequencing on an Illumina MiSeq platform.

\subsection{Bioinformatical Analyses}

13,075,423 raw reads from the V3-V4 16S region were analyzed through the dada 2 pipeline [32]. Quality control of reads was processed through the filterAndTrim() function by using the following parameters: 270 for the read truncation length, 2 as the phred score threshold for total read removal, and a maximum expected error of 2 for forward reads and 4 for reverse reads. The filtered reads were then fed to the error rate learning, dereplication and amplicon sequence variant (ASV) inference steps using the functions learnErrors(), derepFastq() and dada(). Chimeric sequences were removed using the removeBimeraDenovo() function with the "consensus" method parameter. Taxonomic classification was done through the assignTaxonomy() function using the SILVA132 database as a reference. A total of 2946 ASVs was obtained. Unidentified ASVs and those representing less than $0.0005 \%$ of relative abundance were filtered out. At the end of this process, 2423 ASVs were kept for statistical analyses.

\subsection{Statistical Analysis}

Statistical analyses were performed using R software (v 3.3.1, Vienna, Austria). All $p$-values were adjusted with the Benjamini-Hochberg method to reduce the false discovery rate.

Relative abundance plots were generated using only bacterial families having a value of $0.5 \%$ or more that were present in at least $25 \%$ of the samples. The mean relative abundance of each bacterial family was calculated for each sampling time. Data were fitted using a mixed linear model that included the apiary as a random factor. An ANOVA was performed on the model, followed by Tukey's HSD test to see if any group differed significantly from the others.

The $\alpha$-diversity of the honeybee microbiota informs us on the bacterial diversity found in individual samples. It was measured using two indexes, Chao1 and the Shannon index (using the vegan package in R). Comparisons of the indexes between sampling times were carried out as for the relative bacterial abundance.

To determine the $\beta$-diversity of the samples, both unweighted and weighted UniFrac distance metrics were used. The UniFrac distance metric uses phylogeny to compare bacterial communities between samples. Unweighted UniFrac distance only considers the presence of bacterial taxa, and weighted UniFrac also accounts for their abundance. A PERMANOVA was carried out to compare the microbial communities between sampling times. A PCoA for each metric was performed in order to visualize the clustering of the microbial samples.

Co-occurrence and co-avoidance of bacterial taxa were calculated with Spearman correlations (using the Hmisc package in R) and p-values were corrected with FDR for multiple comparison bias. Positive correlations indicated co-occurrence and negative correlations indicated co-avoidance. Networks were generated with Cytoscape (v.3.7.2, Boston, MA, USA) using correlations with $\mathrm{R}^{2}$ values higher or equal to $|0.3|$. 


\section{Results}

\subsection{Overall Microbiota Composition}

Bacterial analysis using V3-V4 16S rDNA amplicon libraries revealed that over 90\% of the honeybee bacterial microbiota sampled in the control group is dominated by seven bacterial families (Figure 1): Acetobacteriaceae (Bombella sp., Commensalibacter sp.), Bifidobacteriaceae, Enterobacteriaceae (Arsenophonus sp., Pantoea sp.), Lactobacillaceae, Neisseriaceae (Snodgrassella sp.), Orbaceae (Frischella sp., Gilliamella sp.) and Rhizobiaceae (Bartonella sp.). Together, they constitute the core microbiota of these honeybees. In June, Enterococcaceae represented nearly $40 \%$ of the gut microbiota of colony E. Since this was the only colony in which this bacterial family was found, we removed it from the analyses.

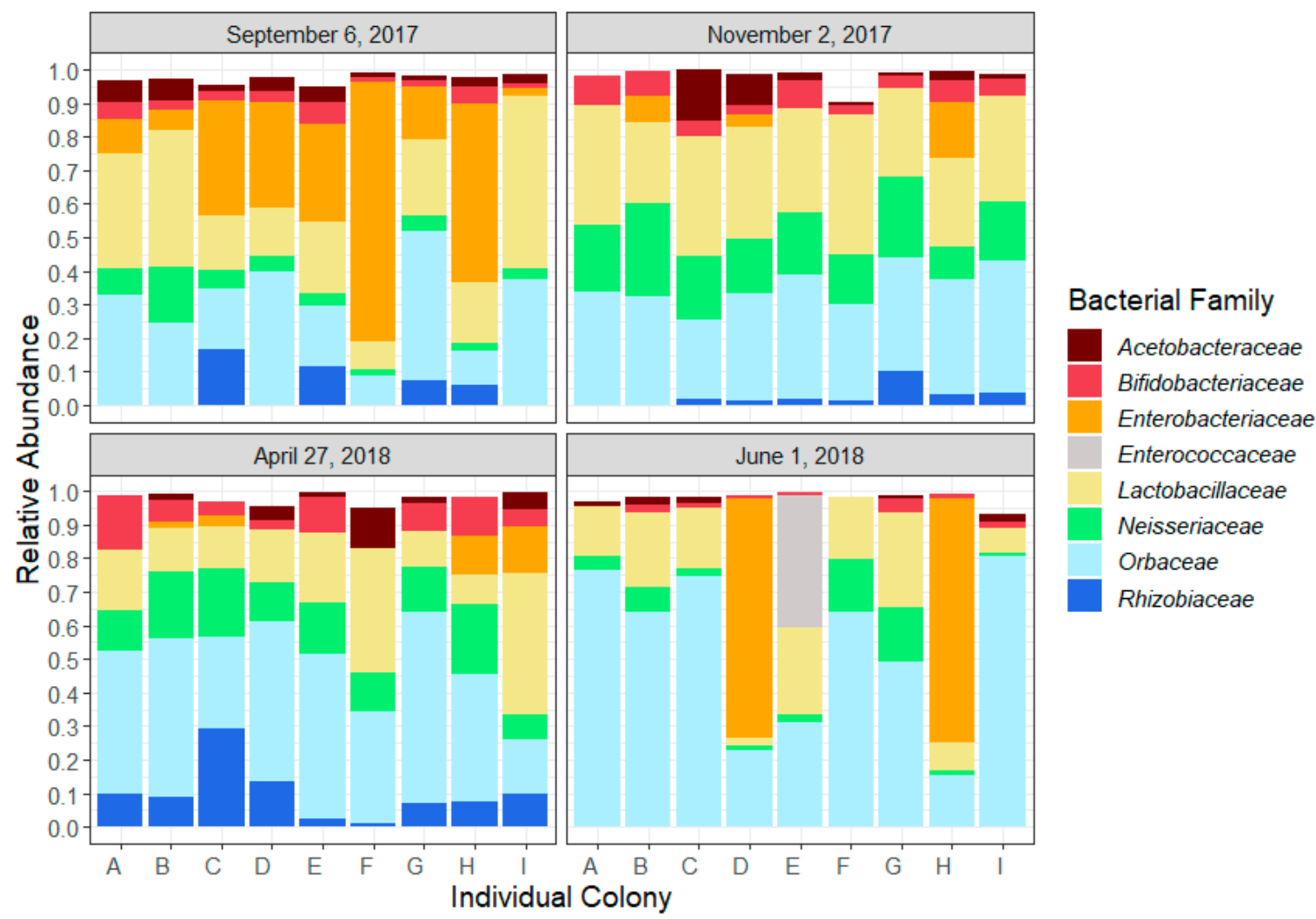

Figure 1. Relative abundance of the core microbiota of the nine colonies (A-I) at the four key sampling moments: September 6, after the last honey flow; November 2, before entering wintering room; April 27, after wintering and removal from wintering room; June 1, during first honey flow of 2018. Bacterial families representing at least $0.5 \%$ of the total abundance in $25 \%$ of the samples of more are presented.

\subsection{Seasonal Trends}

The honeybee gut microbial composition followed a seasonal trend related to the key sampling dates (Figure 1) and significant differences in relative abundance of bacterial families were observed between sampling times (Table 1). In fall, from September to November, the relative abundance of Neisseriaceae increased ( $\mathrm{t}$-ratio $=-5.345, p<0.0001$ ), while Enterobacteriaceae abundance decreased slightly ( $\mathrm{t}$-ratio $=2.747, p=0.06$ ). Between November and April, the relative abundance of Rhizobiaceae increased ( $\mathrm{t}$-ratio $=-2.894, p=0.02$ ). In spring, from April to June, we observed a reduction of three core constituents: Bifidobacteriaceae (t-ratio $=4.319, p=0.0009)$, Neisseriaceae $(\mathrm{t}$-ratio $=3.683$, $p=0.0014)$ and Rhizobiaceae ( $\mathrm{t}$-ratio $=3.908, p=0.002)$. From September to June, Orbaceae increased significantly (t-ratio $=-3.711, p=0.005)$. The only bacterial family that remained stable for the entire study was Acetobacteriaceae. 
Table 1. Statistical analyses and pairwise comparisons of relative abundance of each bacterial family forming the core microbiota between the four sampling times: September 6, after the last honey flow; November 2, before entering wintering room; April 27, after wintering and removal from wintering room; June 1, during first honey flow of 2018. Sampling times are significantly different if they are identified with different letters.

\begin{tabular}{cccccccc}
\hline & & & \multicolumn{4}{c}{ Pairwise Comparison } \\
\hline & F-Value & $\boldsymbol{p}$-Value & Sept. 6 & Nov. 2 & Apr. 27 & Jun. 1 \\
\hline & Acetobacteriaceae & 1.28 & 0.29 & $\mathrm{~A}$ & $\mathrm{~A}$ & $\mathrm{~A}$ & $\mathrm{~A}$ \\
& Bifidobacteriaceae & 7.15 & 0.0009 & $\mathrm{AB}$ & $\mathrm{BC}$ & $\mathrm{C}$ & $\mathrm{A}$ \\
& Enterobacteriaceae & 3.21 & 0.036 & $\mathrm{~A}$ & $\mathrm{~B}$ & $\mathrm{AB}$ & $\mathrm{AB}$ \\
Bacterial family & Lactobacillaceae & 3.59 & 0.024 & $\mathrm{AB}$ & $\mathrm{A}$ & $\mathrm{AB}$ & $\mathrm{B}$ \\
& Neisseriaceae & 14.41 & $<0.0001$ & $\mathrm{~A}$ & $\mathrm{~B}$ & $\mathrm{~B}$ & $\mathrm{~A}$ \\
& Orbaceae & 5.02 & 0.006 & $\mathrm{~A}$ & $\mathrm{~A}$ & $\mathrm{AB}$ & $\mathrm{B}$ \\
& Rhizobiaceae & 5.51 & 0.003 & $\mathrm{AB}$ & $\mathrm{A}$ & $\mathrm{B}$ & $\mathrm{A}$ \\
\hline
\end{tabular}

We observed many co-occurrence and co-avoidance trends (Figure 2), but none were significant. Members of Orbaceae were positively correlated to Neisseriaceae and Bifidobacteriaceae in September, November and April, but there was a negative correlation between Orbaceae and Bifidobacteriaceae in June. The abundance of Enterobacteriaceae was negatively correlated with most taxa during our study, except Rhizobiaceae. However, in June, Enterobacteriaceae was positively correlated to Bifidobacteriaceae.

A

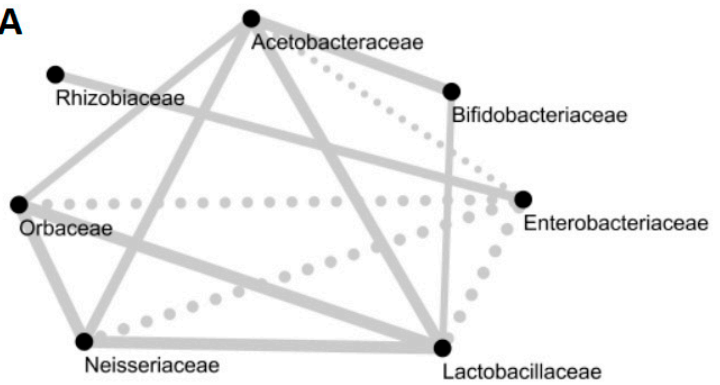

C

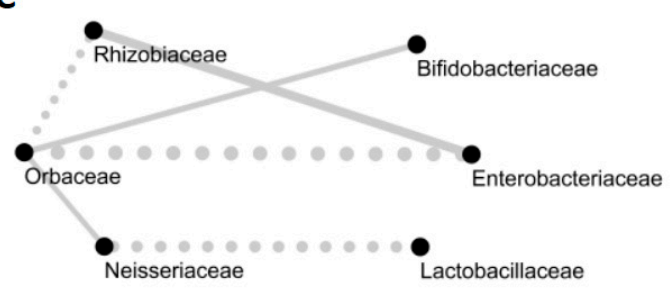

B
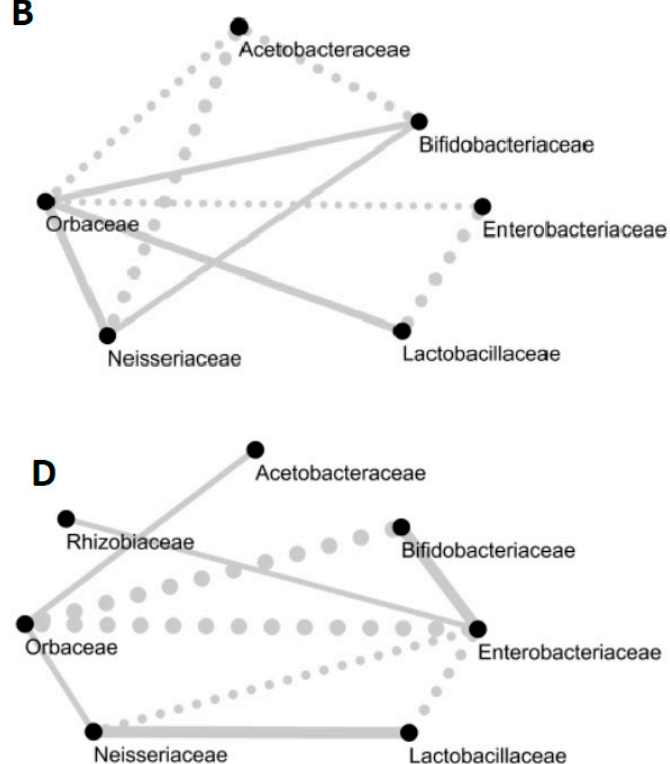

Figure 2. Networks of the core bacterial families of the honeybee gut on (A) September 6, (B) November 2, (C) April 27 and (D) June 1. Full lines indicate a positive correlation and dotted lines indicate negative correlations. Correlations under 0.3 are not displayed in the networks. The thickness of the line is proportional to the value of the correlation between two families.

During our study, the sampling time impacted the two indexes we used to assess $\alpha$-diversity (Figure 3), Chao1 ( $\mathrm{F}=13.26, p<0.0001)$ and the Shannon index $(\mathrm{F}=4.68, p=0.008)$. Chao1 was significantly lower in November compared to September $(p<0.001)$, remained stable during the overwintering period ( $p=0.092)$ and decreased significantly between April and June $(p=0.002)$. Shannon's diversity index followed the same trend as Chao1, but only the difference between September and June was significant ( $p=0.0059)$. 

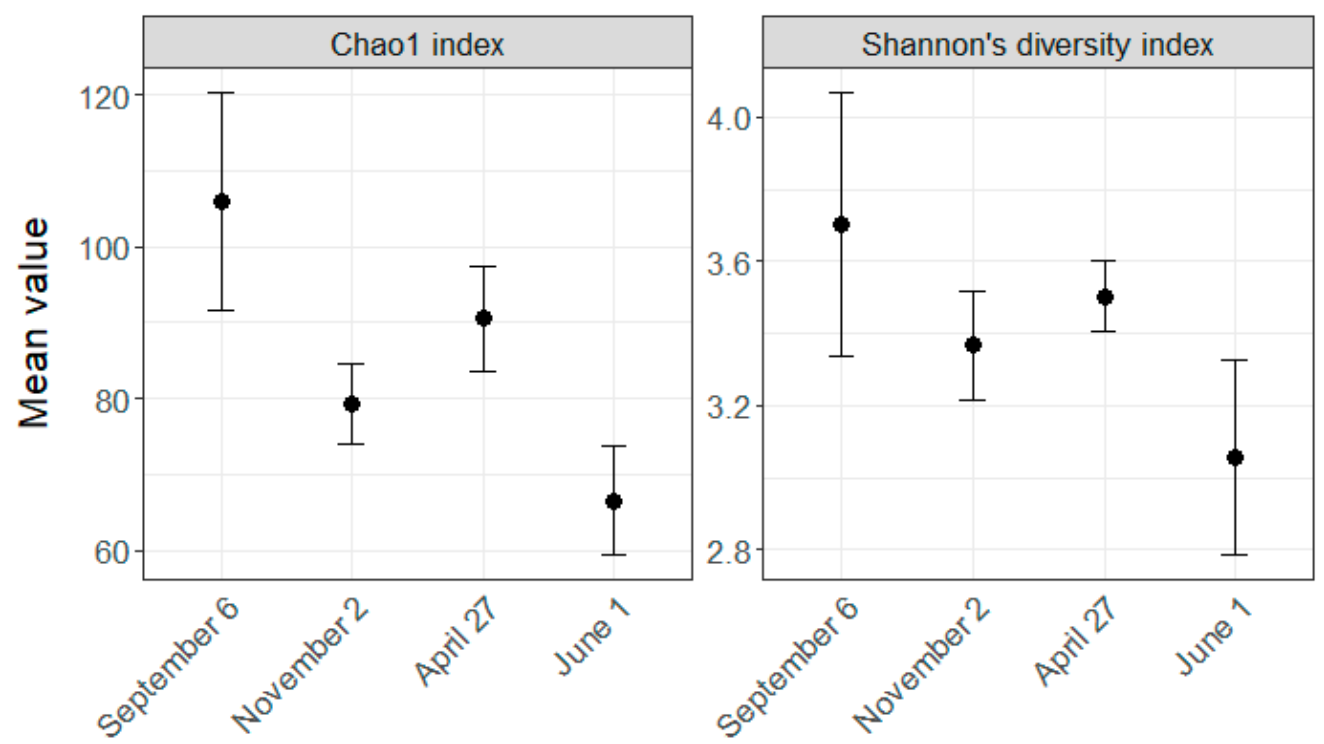

\section{Sampling Moment}

Figure 3. Alpha diversity of the gut microbiota regarding the four key sampling moments. Diversity was measured with Chao1 and Shannon's diversity index. The overwintering period was from November 22 to April 20. Error bars indicate 95\% confidence intervals.

The principal coordinate analysis (PCOA) plots were generated using an unweighted or weighted UniFrac distance metric (Figure 4). Both plots show that samples are clustered by sampling time. The PCoA plot using unweighted UniFrac distances, which only considers the presence of bacterial species, shows that there is an important difference between the bees sampled in September and the other samples. This difference is smaller in the weighted Unifrac PCoA plot, where the abundance of each bacterial specie is also accounted for. Based on the results of the pairwise PERMANOVA, the sampling time did impact both weighted and unweighted UniFrac distance. All pairwise comparisons between sampling times were significant $(p<0.01)$.
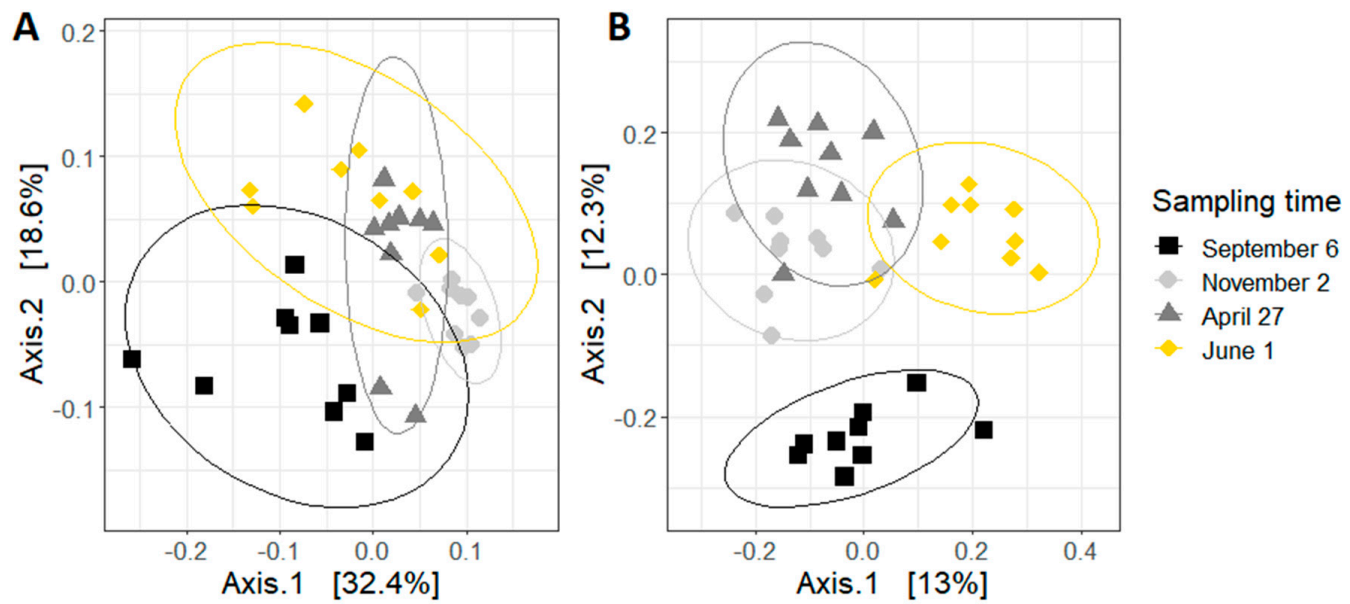

Figure 4. Principal coordinate analysis (PCoA) based on (A) unweighted and (B) weighted UniFrac distance of samples. Each point represents a colony. Ellipses indicate the 95\% confidence intervals.

\section{Discussion}

This study aimed to determine the dynamic of the honeybee gut microbiota in a northern temperate climate at four key times from September to June. During this period of the year, honeybees feed on a poor diet mainly consisting of sugar syrup and aged beebread. Moreover, honeybees are confined in 
their hives, which makes it impossible for them to flush their intestinal content. These two features specific to the wintering period are likely to impact the honeybee gut microbiota. Overall, our results reveal a strong influence of the sampling time on both alpha (Chao1, Shannon) and beta (UniFrac) diversity metrics of the microbiota, as well as its composition.

As expected, the bacterial composition of the microbiota was consistent with the findings of other studies, as the same bacterial families formed the core gut microbiota [33,34]. In addition, the gut microbiota of the colonies monitored in the present study were dominated by Enterobacteriaceae, especially in September. Most strains from this family were identified as Arsenophonus sp. and Pantoea sp. Strains belonging to Enterobacteriaceae are often associated with gastrointestinal diseases in mammals $[35,36]$. In the honeybee, the Enterobacteriaceae family is positively correlated with gut dysbiosis [33] and unhealthy colonies [37]. In one study on colonies suffering from Colony Collapse Disorder, the abundance of Arsenophonus sp. was abnormally high [38]. While the direct impact of the presence of Enterobacteriaceae is still unknown, its abundance in the gut of the honeybees could indicate a health issue that should be investigated further.

We also observed that Enterobacteriaceae was negatively correlated with Lactobacillaceae, Orbaceae and Neisseriaceae. Members of these beneficial bacterial families contribute to the innate immune system of the honeybee by stimulating the production of antimicrobial peptides [39]. These molecules could inhibit the growth of Enterobacteriaceae, explaining the antagonist relationship observed here.

In our study, the composition of the honeybee gut microbiota followed a seasonal trend. The abundance of Rhizobiaceae increased between November and April, but nearly disappeared in spring, after the colonies were taken out of the wintering room. This taxon is frequently found in the honeybee gut, but its impact on the health of the host remains unknown [23]. Interestingly, high levels of Rhizobiaceae have previously been associated to bees fed only with sugar syrup [40]. Not surprisingly, our overwintering honeybees, almost exclusively fed with sugar syrup, exhibited a high level of Rhizobiaceae. Furthermore, the decrease of Rhizobiaceae observed in April coincided with fresh nectar intake. It is therefore very likely that the transition from sugar syrup triggered the important reduction of Rhizobiaceae we observed.

Members of Neisseriaceae, mostly represented by S. alvi, also followed a seasonal trend: an increase in fall, followed by a significant reduction in spring. The bacterium $S$. alvi is known to protect the honeybee gut against opportunistic pathogens by maintaining the intestinal environment anoxic [11] and forming a protective mucopolysaccharide layer on top of the epithelial cells [41]. During the winter season, the bees are clustered within the hive and do not defecate. Therefore, the increase of Neisseriaceae during this period could protect their gut against potential pathogens accumulated in the feces until they can excrete them in spring.

We noted that the presence of Neisseriaceae was negatively correlated to that of Enterobacteriaceae. It has been shown that the availability of oxygen limits the growth of Enterobacteriaceae [42]. Here, we hypothesize that the abundance of Enterobacteriaceae depended partly on the presence of S. alvi, which regulates the amount of oxygen available in the gut. However, in fall, the decrease of Enterobacteriaceae could be related to the anti-varroa treatments administered in October (Thymovar ${ }^{\circledR}$ ) and November (oxalic acid). Members of the Enterobacteriaceae family are among the main symbionts of Varroa destructor [18,43], and because of horizontal transfer between the mites and the honeybees [44], parasitized bees usually harbor higher levels of Enterobacteriaceae strains in their gut. Thus, lowering the infestation levels with varroacides may have reduced the abundance of Enterobacteriaceae, allowing the population of $S$. alvi to increase. However, laboratory trials are needed to confirm the antagonistic relationship between these two bacterial taxa.

Between September and November, colonies were treated twice against $V$. destructor with two acaricides, Thymovar ${ }^{\circledR}$ and oxalic acid, which could explain some of the bacterial shifts we observed during this period. In fact, exposure to common acaricides is known to alter the bees' gut microbiota [45]. Coumaphos triggers an increase of Bifidobacteriaceae in the gut of treated bees, while tau-fluvanilate influences both Rhizobiaceae and Enterobacteriaceae abundance. Moreover, exposure to thymol, the active 
compound of Thymovar ${ }^{\circledR}$, was observed to alter the abundance of many Lactobacillaceae strains in chickens [46].

The microbial richness and diversity of the gut microbiota were lower in June than in September, which is consistent with previous observations [14]. Moreover, the comparison of temporal samples using unweighted and weighted UniFrac metrics showed that the higher diversity measured in September samples was mostly explained by rare taxa. Such a high diversity and quantity of rare taxa observed at the end of the foraging season are both likely due to the bees' access to an abundance of food harboring a variety of microorganisms that are able to colonize their gut, temporarily or permanently [30]. From November to April (during the wintering period), we observed that the diversity of the microbiota remained stable. This result is not surprising: from November to April, bees are confined in their hives, with no fresh food brought to the colony. Consequently, there are no new microorganisms present in the environment to populate the gut of the bees.

The reduction of the bacterial diversity we observed during our study could be partially explained by the varying growth rate of the colonies. Recently, Ribières et al. compared the gut microbial diversity of non-thriving hives, characterized by slow brood development and low honey production, to that of thriving hives [47]. They found that non-thriving hives had a significantly lower gut diversity that thriving hives. At the beginning of the overwintering period, honeybee colonies reduce their brood rearing and honey production, which is similar to non-thriving colonies. However, in spring, even if colonies increase their brood rearing and honey production, we noted that the bacterial diversity still declined. It is possible that environmental factors specific to the overwintering period had a greater impact on the diversity of the gut microbiota than the growth rate of the colonies, hence the opposite observations.

With this study, we showed that the relative abundance of many bacterial taxa that make up the honeybee microbiota, as well as their diversity, follow a seasonal trend. As discussed, it is likely that the bacterial community was modulated by the weather, nutritional and behavioral changes occurring before and after winter. However, the contribution of each individual factor to the modulation of the honeybee microbiota, and consequently honeybee health, needs to be investigated. Trials using caged honeybees could allow each factor to be isolated, so that their individual and collective impact on bee microbiota, health and physiology can be monitored. The results would allow us to develop innovative bee-specific probiotic formulas.

Author Contributions: Conceptualization, P.G. and N.D.; Data curation, N.B.; Formal analysis, N.B. and S.B.; Funding acquisition, P.G. and N.D.; Methodology, N.B.; Visualization, N.B.; Writing-original draft, N.B.; Writing-review and editing, S.B., P.G. and N.D. All authors have read and agreed to the published version of the manuscript.

Funding: This research was funded by Project Apis m.: MOU-021816.

Conflicts of Interest: The authors declare no conflict of interest. The funders had no role in the design of the study; in the collection, analyses or interpretation of data; in the writing of the manuscript, or in the decision to publish the results.

\section{References}

1. Peterson, J.; Garges, S.; Giovanni, M.; McInnes, P.; Wang, L.; Schloss, J.A.; Bonazzi, V.; McEwen, J.E.; Wetterstrand, K.A.; Deal, C.; et al. The NIH Human Microbiome Project. Genome Res. 2009, 19, $2317-2323$. [CrossRef] [PubMed]

2. Anderson, K.E.; Ricigliano, V.A. Honey bee gut dysbiosis: A novel context of disease ecology. Curr. Opin. Insect Sci. 2017, 22, 125-132. [CrossRef] [PubMed]

3. Moran, N.A. Genomics of the honey bee microbiome. Curr. Opin. Insect Sci. 2015, 10, 22-28. [CrossRef]

4. Romero, S.; Nastasa, A.; Chapman, A.; Kwong, W.K.; Foster, L.J. The honey bee gut microbiota: Strategies for study and characterization. Insect Mol. Biol. 2019, 28, 455-472. [CrossRef] [PubMed]

5. Hamdi, C.; Balloi, A.; Essanaa, J.; Crotti, E.; Gonella, E.; Raddadi, N.; Ricci, I.; Boudabous, A.; Borin, S.; Manino, A.; et al. Gut microbiome dysbiosis and honeybee health. J. Appl. Entomol. 2011, 135, 524-533. [CrossRef] 
6. Alberoni, D.; Gaggia, F.; Baffoni, L.; Di Gioia, D. Beneficial microorganisms for honey bees: Problems and progresses. Appl. Microbiol. Biotechnol. 2016, 100, 9469-9482. [CrossRef] [PubMed]

7. Engel, P.; Martinson, V.G.; Moran, N.A. Functional diversity within the simple gut microbiota of the honey bee. Proc. Natl. Acad. Sci. USA 2012, 109, 11002-11007. [CrossRef] [PubMed]

8. Janashia, I.; Choiset, Y.; Rabesona, H.; Hwanhlem, N.; Bakuradze, N.; Chanishvili, N.; Haertlé, T. Protection of honeybee Apis mellifera by its endogenous and exogenous lactic flora against bacterial infections. Ann. Agrar. Sci. 2016, 14, 177-181. [CrossRef]

9. Jefferson, J.M.; Dolstad, H.A.; Sivalingam, M.D.; Snow, J.W. Barrier immune effectors are maintained during transition from nurse to rorager in the honey bee. PLoS ONE 2013, 8. [CrossRef]

10. Lamei, S.; Stephan, J.G.; Riesbeck, K.; Vasquez, A.; Olofsson, T.; Nilson, B.; de Miranda, J.R.; Forsgren, E. The secretome of honey bee-specific lactic acid bacteria inhibits Paenibacillus larvae growth. J. Apic. Res. 2019, 58, 405-412. [CrossRef]

11. Zheng, H.; Powell, J.E.; Steele, M.I.; Dietrich, C.; Moran, N.A. Honeybee gut microbiota promotes host weight gain via bacterial metabolism and hormonal signaling. Proc. Natl. Acad. Sci. USA 2017, 114, 4775-4780. [CrossRef] [PubMed]

12. Raymann, K.; Moran, N.A. The role of the gut microbiome in health and disease of adult honey bee workers. Curr. Opin. Insect Sci. 2018, 26, 97-104. [CrossRef] [PubMed]

13. Powell, J.E.; Martinson, V.G.; Urban-Mead, K.; Moran, N.A. Routes of acquisition of the gut microbiota of the honey bee Apis mellifera. Appl. Environ. Microbiol. 2014, 80, 7378-7387. [CrossRef]

14. Ludvigsen, J.; Rangberg, A.; Avershina, E.; Sekelja, M.; Kreibich, C.; Amdam, G.; Rudi, K. Shifts in the midgut/pyloric microbiota composition within a honey bee apiary throughout a season. Microbes Environ. 2015, 30, 235-244. [CrossRef]

15. Miller, D.L.; Parish, A.J.; Newton, I.L.G. Transitions and transmission: Behavior and physiology as drivers of honey bee-associated microbial communities. Curr. Opin. Microbiol. 2019, 50, 1-7. [CrossRef]

16. Huang, W.F.; Solter, L.F.; Yau, P.M.; Imai, B.S. Nosema ceranae escapes fumagillin control in honey bees. PLoS Pathog. 2013, 9. [CrossRef]

17. Maes, P.W.; Rodrigues, P.A.P.; Oliver, R.; Mott, B.M.; Anderson, K.E. Diet-related gut bacterial dysbiosis correlates with impaired development, increased mortality and Nosema disease in the honeybee (Apis mellifera). Mol. Ecol. 2016, 25, 5439-5450. [CrossRef]

18. Hubert, J.; Bicianova, M.; Ledvinka, O.; Kamler, M.; Lester, P.J.; Nesvorna, M.; Kopecky, J.; Erban, T. Changes in the bacteriome of honey bees sssociated with the parasite Varroa destructor, and pathogens Nosema and Lotmaria passim. Microb. Ecol. 2017, 73, 685-698. [CrossRef]

19. Marche, M.G.; Satta, A.; Floris, I.; Pusceddu, M.; Buffa, F.; Ruiu, L. Quantitative variation in the core bacterial community associated with honey bees from Varroa-infested colonies. J. Apic. Res. 2019, 58, 444-454. [CrossRef]

20. Sandionigi, A.; Vicario, S.; Prosdocimi, E.M.; Galimberti, A.; Ferri, E.; Bruno, A.; Balech, B.; Mezzasalma, V.; Casiraghi, M. Towards a better understanding of Apis mellifera and Varroa destructor microbiomes: Introducing "phyloh" as a novel phylogenetic diversity analysis tool. Mol. Ecol. Resour. 2015, 15, 697-710. [CrossRef]

21. Rubanovl, A.; Russell, K.A.; Rothman, J.A.; Nieh, J.C.; McFrederick, Q.S. Intensity of Nosema ceranae infection is associated with specific honey bee gut bacteria and weakly associated with gut microbiome structure. Sci. Rep. 2019, 9. [CrossRef]

22. Diaz, T.; del-Val, E.; Ayala, R.; Larsen, J. Alterations in honey bee gut microorganisms caused by Nosema spp. and pest control methods. Pest Manag. Sci. 2019, 75, 835-843. [CrossRef]

23. Raymann, K.; Shaffer, Z.; Moran, N.A. Antibiotic exposure perturbs the gut microbiota and elevates mortality in honeybees. PLoS Biol. 2017, 15, 22. [CrossRef] [PubMed]

24. Canadian Association of Professional Apiculturists. Statement on Honey Bee Wintering Losses in Canada. Available online: http://www.capabees.com/shared/2017-2018-CAPA-Statement-on-Colony-Losses-FinalJuly-19.pdf (accessed on 10 December 2019).

25. Doke, S.K.; Dhawale, S.C. Alternatives to animal testing: A review. Saudi Pharm. J. 2015, 23, 223-229. [CrossRef]

26. Fukuda, H.; Sakagami, F.S. Worker Brood Survival in Honeybees. Res. Popul. Ecol. 1968, 10, 31-39. [CrossRef]

27. Phillips, E.F.; Demuth, G.S. Temperature of the honeybee cluster in winter. Bull. US Dep. Agric. 1914, 93, $1-16$. 
28. Crailsheim, K.; Hrassnigg, N.; Gmeinbauer, R.; Szolderits, M.J.; Schneider, L.H.W.; Brosch, U. Pollen utilization in non-breeding honeybees in winter. J. Insect Physiol. 1993, 39, 369-373. [CrossRef]

29. Fries, I. Nosema ceranae in European honey bees (Apis mellifera). J. Invertebr. Pathol. 2010, 103, S73-S79. [CrossRef]

30. Gilliam, M. Identification and roles of non-pathogenic microflora associated with honey bees. FEMS Microbiol. Lett. 1997, 155, 1-10. [CrossRef]

31. Aljanabi, S.M.; Martinez, I. Universal and rapid salt-extraction of high quality genomic DNA for PCR-based techniques. Nucleic Acids Res. 1997, 25, 4692-4693. [CrossRef]

32. Callahan, B.; McMurdie, P.; Rosen, M.; Han, A.; Johnson, A.; Holmes, S. DADA2: High-resolution sample inference from Illumina amplicon data. Nat. Methods 2016, 13, 581-583. [CrossRef] [PubMed]

33. Kwong, W.K.; Moran, N.A. Gut microbial communities of social bees. Nat. Rev. Microbiol. 2016, 14, 374-384. [CrossRef]

34. Rothman, J.A.; Carroll, M.J.; Meikle, W.G.; Anderson, K.E.; McFrederick, Q.S. Longitudinal effects of supplemental forage on the honey bee (Apis mellifera) microbiota and inter-and intra-colony variability. Microb. Ecol. 2018, 76, 814-824. [CrossRef] [PubMed]

35. Mahnic, A.; Breskvar, M.; Dzeroski, S.; Skok, P.; Pintar, S.; Rupnik, M. Distinct types of gut microbiota dysbiosis in hospitalized gastroenterological patients are disease non-related and characterized with the predominance of either Enterobacteriaceae or Enterococcus. Front. Microbiol. 2020, 11. [CrossRef] [PubMed]

36. Pilla, R.; Suchodolski, J.S. The role of the canine gut microbiome and metabolome in health and gastrointestinal disease. Front. Vet. Sci. 2020, 6, 498. [CrossRef] [PubMed]

37. Budge, G.E.; Adams, I.; Thwaites, R.; Pietravalle, S.; Drew, G.C.; Hurst, G.D.D.; Tomkies, V.; Boonham, N.; Brown, M. Identifying bacterial predictors of honey bee health. J. Invertebr. Pathol. 2016, 141, 41-44. [CrossRef]

38. Cornman, R.S.; Tarpy, D.R.; Chen, Y.P.; Jeffreys, L.; Lopez, D.; Pettis, J.S.; van Engelsdorp, D.; Evans, D. Pathogen webs in collapsing honey bee colonies. PLOS ONE 2012, 7. [CrossRef]

39. Kwong, W.K.; Mancenido, A.L.; Moran, N.A. Immune system stimulation by the native gut microbiota of honey bees. R. Soc. Open Sci. 2017, 4, 170003. [CrossRef] [PubMed]

40. D’Alvise, P.; Bohme, F.; Codrea, M.C.; Seitz, A.; Nahnsen, S.; Binzer, M.; Rosenkranz, P.; Hasselmann, M. The impact of winter feed type on intestinal microbiota and parasites in honey bees. Apidologie 2018, 49, 252-264. [CrossRef]

41. Martinson, V.G.; Moy, J.; Moran, N.A. Establishment of characteristic gut bacteria during development of the honeybee worker. Appl. Environ. Microbiol. 2012, 78, 2830-2840. [CrossRef]

42. Rivera-Chavez, F.; Lopez, C.A.; Baumler, A.J. Oxygen as a driver of gut dysbiosis. Free Radic. Biol. Med. 2017, 105, 93-101. [CrossRef] [PubMed]

43. Pakwan, C.; Kaltenpoth, M.; Weiss, B.; Chantawannakul, P.; Jun, G.; Disayathanoowat, T. Bacterial communities associated with the ectoparasitic mites Varroa destructor and Tropilaelaps mercedesae of the honey bee (Apis mellifera). FEMS Microbiol. Ecol. 2018, 94. [CrossRef] [PubMed]

44. Hubert, J.; Kamler, M.; Nesvorna, M.; Ledvinka, O.; Kopecky, J.; Erban, T. Comparison of Varroa destructor and worker honeybee microbiota within hives indicates shared bacteria. Microb. Ecol. 2016, 72, 448-459. [CrossRef] [PubMed]

45. Kakumanu, M.L.; Reeves, A.M.; Anderson, T.D.; Rodrigues, R.R.; Williams, M.A. Honey bee gut microbiome is altered by in-hive pesticide exposures. Front. Microbiol. 2016, 7. [CrossRef] [PubMed]

46. Yin, D.; Du, E.; Yuan, J.; Gao, J.; Wang, Y.; Aggrey, S.E.; Guo, Y. Supplemental thymol and carvacrol increases ileum Lactobacillus population and reduces effect of necrotic enteritis caused by Clostridium perfringes in chickens. Sci. Rep. 2017, 7, 7334. [CrossRef] [PubMed]

47. Ribière, C.; Hegarty, C.; Stephenson, H.; Whelan, P.; O'Toole, P.W. Gut and whole-body microbiota of the honey bee Separate thriving and non-thriving hives. Microb. Ecol. 2019, 78, 195-205. [CrossRef]

(C) 2020 by the authors. Licensee MDPI, Basel, Switzerland. This article is an open access article distributed under the terms and conditions of the Creative Commons Attribution (CC BY) license (http://creativecommons.org/licenses/by/4.0/). 